\title{
O ESPÍRITO DE HORROR À VIDA EDUCATIVA NOS CAMPOS: A EDUCAÇÃO RURAL PAULISTA NAS DÉCADAS DE 1930 E $1940^{1}$
}

\author{
Macioniro Celeste Filho \\ Universidade Estadual Paulista, campus de Bauru, Brasil.
}

$\cos 80$

\section{Resumo}

Nas décadas de 1930 e 1940 o sistema escolar paulista se consolidou em nova organização institucional em todo o Estado. Administradores escolares, os delegados regionais do ensino, organizaram em novo patamar a educação primária neste período. No espaço urbano, os grupos escolares eram o modelo a ser seguido. Contudo, como se encontravam as escolas rurais? Apresenta-se neste trabalho a visão destes delegados de ensino sobre a situação da educação rural em São Paulo neste período. O texto aborda o conflito entre a realidade cotidiana do sistema escolar possível e o ideal almejado para a educação rural no Estado de São Paulo. Os documentos utilizados foram os relatórios destes administradores escolares, preservados no Arquivo Público do Estado de São Paulo.

Palavras-chave: escolas rurais, escolas isoladas, história da educação, ensino primário paulista.

\section{THE SPIRIT OF HORROR TO EDUCATIONAL LIFE IN THE COUNTRY: THE RURAL EDUCATION IN THE STATE OF SÃO PAULO IN THE 1930s AND 1940s}

\begin{abstract}
In the 1930s and 1940s, the school system was consolidated in new institutional organization in the State of São Paulo. School administrators, the regional teaching delegates organized in a new level the primary education in this period. In urban areas, school groups were the model to be followed. However, how the rural schools were? This paper will present the vision of these teaching delegates about the calamitous situation of the rural education in São Paulo during this period. This text will address the conflict between the everyday reality of the feasible school system and the targeted ideal for rural education in São Paulo. The source material utilized for this study contemplates the reports of the school administrators preserved in the Public Archives of the State of São Paulo.
\end{abstract}

Key-words: rural schools, isolated schools, history of education, primary education of the State of São Paulo.

${ }^{1}$ Este trabalho é resultado parcial das pesquisas para o projeto História da Escola Primária Rural no Estado de São Paulo (1931-1968): circulação de referenciais estrangeiros, iniciativas do Poder Público e cultura escolar, coordenado pela professora Rosa Fátima de Souza, da Unesp de Araraquara, e financiado pela Fapesp. O título é inspirado no texto encontrado na p. 25 do relatório de Piracicaba de 1933. 


\section{EL ESPÍRITU DEL HORROR A LA VIDA EDUCATIVA EN EL CAMPO: LA EDUCACIÓN RURAL EN EL ESTADO DE SÃO PAULO EN LOS AÑOS 1930 Y 1940}

\section{Resumen}

En los años 1930 y 1940 el sistema escolar de São Paulo se ha consolidado en una nueva organización institucional en todo el estado. Administradores escolares, los delegados regionales de la enseñanza organizaron en nuevo nivel la educación primaria en este período. En las ciudades, los grupos escolares fueron el modelo a seguir. Sin embargo, ¿cómo eran las escuelas rurales? En este trabajo se presenta la visión de estos delegados de enseñanza acerca de la grave situación de la educación rural en São Paulo. El texto trata del conflicto entre la realidad cotidiana del sistema escolar posible y el ideal deseado para la educación rural en São Paulo. Como fuente documental se utilizaron los informes de los administradores escolares conservados en el Archivo del Estado de São Paulo.

Palabras-clave: escuelas rurales, escuelas aisladas, historia de la educación, enseñanza primaria en São Paulo.

\section{L'ESPRIT D'HORREUR DE LA VIE EDUCATIF AUX CHAMPS: L'EDUCATION RURALE A SÃO PAULO DANS LES DECENNIES DE 1930 ET 1940}

Résumé

Dans les années 1930 et 1940, le système scolaire a consolidée à São Paulo une nouvelle organisation institutionnelle à travers l'État. Les administrateurs scolaires, les délégués régionaux ont organisés l'enseignement l'enseignement primaire à un neuf niveau dans au cours de cette période. Dans les zones urbaines, les groupes scolaires étaient le modèle à suivre. Cependant, comment se trouvent les écoles rurales? Ce document presentera la vision de ces délégués d'enseignement sur la situation désastreuse de l'éducation rurale. Le texte traite du conflit entre la réalité quotidienne du système scolaire possible et de l'idéal recherché par l'éducation rurale dans São Paulo. Le source documentel utilisé étaient les rapports scolaires, conservés dans les Archives de l'État de São Paulo.

Mots-clé: écoles rurales, écoles isolées, histoire de l'éducation, l'enseignement primaire à São Paulo. 
De um modo geral, as nossas professoras vivem a procura de alunos, os quais, mal alimentados, são na sua maioria raquíticos, apresentando, assim, sérios embaraços à aprendizagem. Contribuindo, também, para o baixo resultado das nossas escolas [rurais] estão a escassez e a impropriedade do nosso material didático, a péssima instalação de muitas escolas e a má residência ou pensão da professora. Acrescente-se a tudo isto a inadequada preparação do mestre, que está técnica e espiritualmente habilitado para as cidades. (Eboli, 1943, p. 4)

descrição acima, de 1943, sobre as escolas rurais no Estado de São Paulo é
de José Ferreira Eboli, delegado regional do ensino de Guaratinguetá. Em
meados da década de 1940, assim como ele, muitos dos responsáveis pela administração do ensino paulista aparentavam cansaço frente às inúmeras e repetitivas críticas às carências do ensino rural de então e com o descaso governamental às suas propostas para solucionar os problemas que relatavam. Esta fadiga se acumulava desde os primeiros relatórios das delegacias regionais do ensino, de 1933.

Este trabalho apresentará a visão de um grupo profissional em posição privilegiada para a análise do ensino rural em São Paulo nas décadas de 1930 e 1940, a dos delegados regionais do ensino. Tais administradores escolares, alguns deles exprofessores de escolas rurais, contaram, freqüentemente, com a ajuda e depoimentos de inspetores escolares, diretores e professores para avaliar as escolas rurais sob sua responsabilidade. Seus relatos têm algo em comum: orgulho dos melhoramentos da educação urbana, contrastando com a profunda indignação com a situação abominável da educação rural do período.

Pouco mais de três meses após a criação do Ministério da Educação e Saúde Pública, foi criada a Secretaria de Estado da Educação e Saúde Pública de São Paulo, em março de 1931. Neste ano, e no seguinte, foram organizadas as delegacias regionais do ensino do Estado de São Paulo. As 21 delegacias regionais tinham como principal incumbência administrar o sistema escolar em consolidação e expansão durante o período varguista. Tais delegacias, periodicamente, prestavam contas de suas atividades à Diretoria Geral do Ensino, na Capital. Para tanto, de 1933 a 1945, elaboraram ao menos 68 relatórios detalhando suas atividades. Estes relatórios encontram-se no Arquivo Público do Estado de São Paulo ${ }^{2}$. Esta documentação foi pesquisada, na sua totalidade, para a compreensão da educação rural em São Paulo neste período. Devido à abundância documental e à riqueza dos relatos, no atual texto não será executado um diálogo destas fontes com os trabalhos de outros autores que já analisaram a educação rural brasileira. Esta interface com a bibliografia referente à educação rural no país ficará para momento posterior.

O que contêm estes relatórios? Num primeiro momento, eles eram bem informais. Segundo a circular n. 25, de 1933, da Diretoria Geral do Ensino, além dos dados estatísticos referentes às escolas de sua região, aos delegados do ensino era solicitado

2 Para maior informação sobre estes relatórios, consultar meu trabalho intitulado Os relatórios das delegacias regionais de ensino do Estado de São Paulo como fonte de pesquisa para a história da educação - décadas de 1930 e 1940. Revista Brasileira de História da Educação. Campinas: SBHE/Autores Associados, v. 12, n. 1, 2012, p. 71-111.

\begin{tabular}{|l|l|l} 
Hist. Educ. [Online] & Porto Alegre & v. 18
\end{tabular}

\begin{tabular}{l|l} 
n. $43 \quad$ Maio/ago. 2014
\end{tabular}

p. $49-70$ 
que "revelem, de modo sucinto e claro [...] os alvitres [sugestões] que nos pareçam mais oportunos e praticáveis no aperfeiçoamento e eficácia dos trabalhos que nos foram entregues" (Corrêa, 1933, p. 1). É em resposta a este pedido que os delegados regionais do ensino formularam uma série de críticas à situação calamitosa das escolas rurais e elaboraram sugestões práticas de como solucionar os problemas enfrentados. Nestas sugestões há pouca discussão teórica, mas forte pragmatismo administrativo, com vistas à corrigir os problemas da educação nas escolas rurais. Posteriormente, os relatórios foram alvo de padronização, normatizados pela circular n. 87, de 16 de dezembro de 1936, e pela circular 86, de 31 de dezembro de 1942, ambas da Diretoria Geral do Ensino.

Como os delegados regionais do ensino identificavam a escola rural? Luiz Damasco Penna, no relatório de Santos referente a 1935, discordava da definição legal:

Pelos textos regulamentares, são rurais as escolas que não estejam em sede de município ou em sede de distrito de paz; e basta que num bairro seja cobrado o imposto predial urbano, para que as escolas dali se digam urbanas. Por outro lado, há populações vivendo no regime civil de urbanas e que são, visceralmente, populações rurais. (Penna, 1935, p. 11)

Isto é, embora muitas das escolas isoladas fossem legalmente urbanas eram, de fato, rurais. No relatório referente a 1936, o mesmo delegado sintetizou que as escolas isoladas eram sinônimo de escolas rurais. Referindo-se às escolas isoladas, afirmou que "a maior dificuldade vem da sua própria condição de ser isolada. Poderíamos quase que tratar já da [escola] isolada rural, pois [escola] isolada urbana é erro grosseiro em administração escolar" (Penna, 1936, p. 101).

Nos relatórios, Luiz Damasco Penna é o delegado regional do ensino mais explícito, direto e contundente em suas afirmações. Contudo, esta identificação entre escola isolada e escola rural poderia ser generalizada para as outras regiões do Estado de São Paulo? É provável que sim. Em diversos outros relatórios encontram-se afirmações neste sentido. São frases curtas, mas aparentemente consensuais, como a do delegado regional do ensino de Ribeirão Preto, Francisco Alves Mourão, no relatório de 1936, p. 27: "A quase totalidade das escolas isoladas da região localiza-se na zona rural".

Portanto, os delegados regionais do ensino, ao criticarem a situação das escolas isoladas referem-se, privilegiadamente, às escolas rurais. Escolas isoladas, predominantemente rurais, tinham um único professor, eram multisseriadas, isto é, o docente ensinava conhecimentos distintos simultaneamente a alunos de níveis e faixas etárias diferentes. Em contraposição, as escolas urbanas se organizaram em grupos escolares, isto é, escolas graduadas, com vários professores lecionando conhecimentos diferentes para alunos agrupados separadamente em salas com níveis e faixas etárias distintas, quando possível, inclusive, com separação entre alunos e alunas. Neste último relatório citado, Francisco Mourão sintetizou os principais problemas enfrentados pelas escolas rurais:

Como dificuldades comuns às escolas isoladas, podemos enumerar, na ordem decrescente dos prejuízos que produzem ao ensino, as seguintes: $1^{\circ}$ - Falta de matrícula e freqüência das escolas, na maioria das vezes, determinadas pelo estado de pobreza das populações. $2^{\circ}$ - Falta de 
estabilidade do professor, por motivos assaz conhecidos e que nos dispensamos de comentar aqui. $3^{\circ}$ - Falta de material escolar, visto que, em algumas fazendas, onde é acentuada a pobreza dos colonos, ninguém pode adquirir material e o fornecido pelo Almoxarifado, nestes casos especiais, não dá para todos os alunos. $4^{\circ}$ - Moléstias comuns à zona rural, tais como tracoma, amarelão, maleita, e a deficiência de alimentação etc., que não são convenientemente combatidas, em conseqüência da ignorância e miserabilidade das populações. $5^{\circ}$ - Falta de instalação condigna das escolas, sabido, como é, que grande número delas funciona em prédios de emergência, sem espaço, sem luz suficiente, sem instalações sanitárias e muitas vezes até com dificuldade para obtenção de água potável. (Mourão, 1936, p. 28)

Seguindo a ordem de dificuldades das escolas rurais apontadas acima, encontra-se, nos relatos dos administradores escolares, muita repetição sobre estes temas. Selecionou-se alguns depoimentos exemplares, com o intuito de mapear a situação das escolas rurais das décadas de 1930 e 1940.

Num dos primeiros relatórios desta série documental, João Teixeira de Lara, delegado regional do ensino de Botucatu, em 1933, ressaltou que

uma das causas que muito contribui para a baixa porcentagem de promoção é, sem dúvida, a falta de estabilidade dos alunos matriculados em estabelecimentos de ensino localizados na zona rural, porque, infelizmente, a gente da roça, não compreendendo a alta finalidade da escola, não the dá o apoio moral indispensável à sua prosperidade. [...] Essa gente, queremos crer, não faz isto por maldade, e sim por ignorância. Vendo que lucrará muito mais mantendo os filhos na roça, relega para o plano inferior a instrução. (Lara, 1933, p. 16)

O Código de Educação do Estado de São Paulo, de 1933, previa a obrigatoriedade de freqüência às escolas das crianças de 8 a 14 anos. Os delegados regionais do ensino conclamaram, muitas vezes, que a Diretoria Geral do Ensino fizesse cumprir a lei. Enquanto isto não ocorria, alguns delegados elaboraram medidas paliativas. João Teixeira de Lara, de Botucatu, em 1933, destacou a importância das festas escolares e do reforço das associações de pais e mestres na manutenção dos alunos nas escolas:

O professor precisaria ser, antes de tudo, um abnegado, vivendo para a sua escola, a fim de conhecer perfeitamente as condições do meio em que vai agir, se quisesse o progresso da causa que abraçou; precisaria, ao encerrar o semestre letivo, ou o ano, promover festas, convidando para assisti-las, os moradores do bairro; realizar estas festas, sempre que possível, em feriados, domingos ou dias santos, para que todos pudessem assisti-las; fundar "Associação de Pais e Mestres", dando aos dirigentes a chefia dos diversos setores em que dividiu o bairro, com os quais se entende diretamente, sempre que necessitasse de reclamar sobre a freqüência de alunos à sua escola. Esses chefes de setores seriam auxiliares dedicadíssimos do professor, pois, recebendo eles a incumbência, com prazer, jamais deixariam periclitar a freqüência da escola, da qual passaram a ser fieis guardas. Feitas todas as propagandas possíveis em benefício da escola, impõe-se a aplicação rigorosa da Lei aos relapsos e transgressores. (Lara, 1933, p. 23) 
Entretanto, o que irritava profundamente os delegados de ensino no que se refere à freqüência às escolas rurais era quando não fossem os pais das crianças a retirar seus filhos para trabalhar nas roças, mas os próprios fazendeiros. Neste caso, preferiam fechar a escola rural e cobrar alguma punição legal. Novamente exigia-se que a Diretoria Geral do Ensino fizesse cumprir a lei. Foi o caso exemplar de fechamento de escola relatado pelo mesmo João Teixeira de Lara, agora delegado regional do ensino de Piracicaba, em 1942:

Ainda continuam alguns fazendeiros e industriais a se mostrarem indiferentes, uns, hostis, outros, para com a escolinha rural. Ainda neste ano, usamos de energia para com um desses magnatas dinheirosos, retirando a escola de sua fazenda, onde eram a professora menosprezada e maltratada e as crianças impedidas de freqüentar as aulas, por causa do trabalho que lhes era imposto na roça. Há uma disposição constitucional, na Carta Magna de 1934, que continua em vigor, por não ter sido revogada pela Constituição do Estado Novo e que está dependendo de execução. É o art. 139, que diz: "Toda a empresa agrícola ou industrial, situada fora dos centros escolares, onde trabalhem mais de cinqüenta pessoas e houver, perfazendo estas e seus filhos, pelo menos 10 analfabetos, será obrigada a Ihes proporcionar instrução primária gratuita". Se estivesse em execução esse dispositivo, ao retirarmos a escola da fazenda de Monte Mor, teríamos intimado o truculento e façanhudo fazendeiro a instalar uma escola por sua conta, em substituição à que acabava de sair. Se há dispositivos legais em vigor e de finalidades tão preciosas, como aqueles que acabamos de apontar, por que não executá-los? Pedimos, pois, ao Sr. Diretor do Departamento de Educação que beneficie o Estado, pondo em execução a lei que dorme. (Lara, 1942, p. 51)

Fora o anterior delegado regional do ensino de Piracicaba, Francisco de Faria Netto, em 1933, quem havia sugerido este dispositivo constitucional:

Enviei ao Dr. Alcântara Machado, chefe da Bancada Paulista à Constituinte, o seguinte cartão: [...] Não seria lícito incluir-se entre os artigos referentes ao ensino a obrigação de todos os proprietários agrícolas ou industriais da zona rural, cuja propriedade contenha mais de 40 crianças em idade escolar, construírem sala de aula com acomodações para uma professora e serem responsabilizados pela freqüência da classe? Não conviria proibir-se aos menores de 15 anos, que não tenham completado o curso primário, todo e qualquer trabalho durante as horas de aula, sob pena de responsabilidade criminal daqueles que sobre eles exercem o pátrio poder, tutela ou curatela? (Netto, 1933, p. 83)

Era angustiante aos administradores escolares constatar que tais dispositivos constitucionais transformaram-se na "lei que dorme" (Lara, 1942, p. 52). Além da Constituição, o Código de Educação do Estado de São Paulo, de 1933, estabelecia que deveria existir uma escola isolada onde houvesse 40 crianças em uma área de dois quilômetros de raio. Estes dispositivos legais seriam as bases para a obrigatoriedade de freqüência das crianças às escolas rurais. Entretanto, esta obrigatoriedade era vista como "lei que dorme" (Lara, 1942, p. 52) por um motivo bem objetivo: não havia escolas para todas as crianças nem nas cidades, quanto mais na zona rural. Luiz Damasco Penna relatou isto para a região de Santos, em 1940: 
A situação é gravíssima e invariavelmente exposta por mim em todos os relatórios anuais. Basta que consideremos os seguintes dados. O Estado só dá instrução a menos de $50 \%$ da população escolar da cidade. Há um quarto de século não faz um grupo escolar, eis que o último, o Visconde de São Leopoldo, foi construído em 1915. [...] Alguns dos [prédios escolares] alugados não os fecha a autoridade sanitária seguramente apenas porque são ocupados pelo próprio Estado. (Penna, 1940, p. 39)

Embora cobrassem a aplicação dos dispositivos constitucionais e a efetiva implantação do Código de Educação de 1933, os administradores escolares constatavam que tal legislação era um conjunto de boas intenções a serem perseguidas como um ideal. Esta postura explica o ceticismo dos delegados regionais do ensino quanto às granjas escolares. Se nem se conseguia implantar escolas isoladas para todos na zona rural, o que dizer de criá-las nos moldes desta proposta exemplar? O Código de Educação estabelecia que futuras granjas escolares possuíssem um edifício com salas de aula, a residência para os professores e, para a sua instalação, a doação para o Estado de três hectares de terra. Sobre estas escolas, Luiz Damasco Penna relatou que

não conheço mesmo a possibilidade de instalação de uma ou mais granjas [escolares] em cada município, nem a cooperação possível da Câmara [Municipal] ou de particulares e conheço escassamente a capacidade de um ou outro professor para a realização efetiva da educação primária rural. [...] Sempre hei de declarar - não me importa que me acoimem de primária a concepção do problema educacional - que escolas se fazem com professor, casa, aparelhamento escolar e meninos. Destes elementos só encontrei, reunidos, os meninos. [...] Uma escola, para ser melhorada, é preciso, primeiro, que exista. [...] Os lugares, aqui, não são, em regra, melhores nem piores que os restantes do Estado. Há, eu sei, paragens aqui quase inabitáveis. Quase, porque lá há 40 crianças que pedem escola. Mas como o Estado não pode dar escola para todos os grupos de 40 crianças existentes no seu território, eu tenho, com prudência, deslocado, sempre que posso, as escolas para os melhores lugares. Com prudência, porque o critério, levado às suas últimas conseqüências, acabaria pondo todas as escolas isoladas na Praça da Catedral, em São Paulo. (Penna, 1935, p. 14)

Outros administrados escolares ressaltaram o principal impedimento para a tentativa de criação das granjas escolares: a necessária doação para o Estado, por parte da comunidade, dos três hectares de terra. Algumas comunidades até cogitariam a criação destas escolas, contanto que as terras fossem cedidas em sistema de comodato, enquanto a escola existisse efetivamente. Collatino Fagundes, delegado regional do ensino de Santa Cruz do Rio Pardo, em 1936, relatou que

no momento não será possível conseguir-se a instalação de granjas escolares do tipo previsto pelo Código de Educação. Isto pela dificuldade de se conseguir a doação da área de terreno para tal fim, exigida no Artigo 257, assim como a imediata construção do prédio com acomodação para o professor. [...] Será possível a instalação de uma granja escolar uma vez que se aceite o terreno necessário em cessão enquanto durar o funcionamento da mesma, em vez de doação como pede o Código. Tratando-se, como é fato, de um novo tipo de escola, ou melhor, de um 
ensaio a se fazer, parece a esta Delegacia [de Ensino] vantajosa a aceitação desta modalidade. (Fagundes, 1936, p. 18)

É provável que a proposta de criação de granjas escolares tenha sido postergada indefinidamente.

Nas palavras anteriormente citadas de Francisco Mourão, de Ribeirão Preto, o segundo fator de fracasso da educação rural seria a "falta de estabilidade do professor, por motivos assaz conhecidos e que nos dispensamos de comentar aqui" (Mourão, 1936, p. 28). Quais eram estes motivos assaz conhecidos que provocavam a desistência dos professores em lecionar numa escola rural? Vários delegados regionais do ensino descreveram a trajetória recorrente dos professores nestas escolas. Collatino Fagundes sintetizou este caminho:

Em geral, o professor é bem recebido [na zona rural], encontrando toda facilidade para o início de sua missão. Pouco tempo depois, salvo raríssimas exceções, ele próprio cria o problema. E o motivo? Muito simples: não ambientado, saudoso dos seus, começa por querer isto e mais aquilo; condução semanal para ir à cidade ouvir missa, fazer pequenas compras ou assistir uma sessão cinematográfica; queixa-se, amiúde, dizendo mais isto ou menos isto: isto aqui não é vida! Deus me livre desta gente atrasada! etc., etc. E a reação vem logo. A dona da casa, até então bondosa e hospitaleira, fazendo às vezes sacrifício para hospedar a professora, dela se desinteressa por completo. E o que temos notado é que por detrás da cortina está um dedinho político, a acenar à professora com a perspectiva de uma transferência da escola para as barbas da cidade, quando não seja logo com a anexação da mesma ao grupo escolar. (Fagundes, 1936, p. 51-52)

No período, era prática comum o professor de escolas rurais solicitar licença pelos mais variados motivos, pedir remoção para escolas urbanas tão logo conseguisse condições para isto ou mesmo se exonerar do cargo. Para se ter uma idéia deste tipo de ocorrência, segundo o relatório de Itapetininga de 1936, das 134 escolas rurais existentes na região, 38 delas, quase um terço, deixaram de funcionar devido à licença dos respectivos professores ou pela remoção dos respectivos titulares. No entanto, nem todos os administradores escolares atribuíam a culpa disto aos próprios professores. Francisco Lopes de Azevedo, delegado regional do ensino de Taubaté, em 1935, ressaltava que "se os nossos grupos escolares são organizações ótimas, as nossas escolas rurais deixam muitíssimo a desejar. O professor tem sido o 'bode expiatório'. Mas ele não é o único culpado, bem o sabemos" (Azevedo, 1935, p. 49).

No mesmo sentido, Oscar Augusto Guelli, delegado regional do ensino de Botucatu, em 1940, afirmava que

não seremos nós, calejados de pecados na tarimba do magistério primário, que iremos atirar a primeira pedra contra a capacidade docente do nosso professorado. O que vai pelos arraiais do ensino primário é conhecido de todos e dispensa comentários. (Guelli, 1940, p. 68)

Usar o professor da escola isolada como bode expiatório pelo fracasso das escolas rurais não pareceu apropriado a muitos dos administradores escolares de então. Porém, o que estava por trás de afirmações como "por motivos assaz conhecidos e que nos 
dispensamos de comentar aqui" (Mourão, 1936, p. 28), "bem o sabemos" (Azevedo, 1935, p. 49) ou "é conhecido de todos e dispensa comentários"? (Guelli, 1940, p. 68). Francisco de Faria Netto, então delegado regional do ensino de Piracicaba, executou uma pesquisa com os cem professores das escolas rurais de sua região para entender, nas suas sempre contundentes palavras, a expressão que dá título ao atual trabalho: "o espírito de horror à vida educativa nos campos" (Netto, 1933, p. 25). Os resultados foram relatados resumidamente em seis páginas, p. 25 frente até a 27 verso do relatório de Piracicaba de 1933. Este administrador escolar concluiu que os principais problemas da educação rural eram as péssimas condições sanitárias das escolas e das residências para os professores. Conseqüentemente, o elevado número de afastamentos para o tratamento médico no combate às constantes doenças que afligiam os docentes:

A água potável das casas rurais, sempre pessimamente decantada, é provinda quando não seja do córrego mais próximo, fatalmente será da cisterna [poço], quase sempre mal conservada. Mais da metade das casas rurais não possui latrina. Predomina, endemicamente, em todos os bairros a verminose, parte pequena [das casas com] tracoma e outra parte [com] a malária. (Netto, 1933, p. 27)

Dos 5.785 lares recenseados pelos professores na zona rural de Piracicaba, somente 1.280 (22\%) tinham serviço sanitário completo. Os outros 4.505 lares (78\%), não tinham este serviço. Em muitos outros relatórios foram apontados os problemas docentes decorrentes do contato com as doenças endêmicas nas zonas rurais. Por exemplo, José Clozel, delegado regional do ensino de São José do Rio Preto, em 1934, afirmou que "em toda a zona, principalmente na rural, grassa o amarelão e a maleita [malária] em caráter endêmico. $O$ tracoma e o tifo são também bastante conhecidos e familiares por aqui" (Clozel, 1934, p. 2).

Os administradores escolares alertaram, também, para a precariedade das moradias dos professores rurais. Ottoni Pompeu Piza, delegado regional do ensino de Araraquara, em 1936, descreveu as dificuldades de hospedagem docente na zona rural:

A residência e pensão [alimentação] para o professor rural tem sido um problema de solução difícil. $O$ fazendeiro pensa que a professora pode viver em qualquer lugar e, não raro, lhe destina uma casa de colono para residência, no caso de ter ela a família em companhia. Quando, porém, a professora é solteira, como na maioria dos casos, vai, geralmente, para a casa do fiscal de colonos ou para a casa do carpinteiro, pedreiro ou maquinista da fazenda. Nunca, porém, para a casa do fazendeiro e, raramente, para a casa do administrador. Em vista da grande diferença de educação existente entre a professora e a família que a hospeda, nenhuma delas se conforma com a situação e a escola fica prejudicada pelo afastamento da professora, que solicita licença como único meio de resolver a situação do momento. (Piza, 1936, p. 28)

Com este panorama de doenças endêmicas, péssimas condições sanitárias e graves problemas de moradia docente, não deve causar surpresa que os professores das escolas rurais quisessem residir nas zonas urbanas mais próximas de suas escolas. Daí a constatação dos administradores educacionais do período sobre a importância do transporte para estes docentes. Francisco Alves Mourão, delegado regional do ensino de 
Ribeirão Preto, em 1936, citando o inspetor escolar Santos Amaro da Cruz, afirmou que "tenho a impressão de que os professores só se sentem bem onde não estão" (Mourão, 1936, p. 35). Ele criticava a viagem diária dos professores entre a cidade e suas escolas na zona rural: "Professores há que [...] arrostam [encaram sem medo] os incômodos das viagens diárias por estradas poeirentas e esburacadas, em péssimas jardineiras [precursoras dos ônibus], sem a mínima segurança, exclusivamente para residirem na cidade" (Mourão, 1936, p. 35).

Citando outro inspetor escolar, Sylvio de Barros, Francisco Mourão relatou que alguns professores não cogitavam pernoitar nas zonas rurais:

Professores que só por necessidade se afastam dos meios urbanos, sem estabilidade, inseguros de sua verdadeira missão, imbuídos de modernismos, viajando diariamente, para trabalhar com os olhos no relógio, o sentido na cidade e os ouvidos no apito dos trens ou na buzina das jardineiras... É verdade que grande número de fazendas ou sítios não oferece o conforto que os professores merecem, nem quanto a prédio de residência, nem quanto à pensão [alimentação]. (Mourão, 1936, p. 35)

Outra reclamação constante dos administradores escolares refere-se à escassez e baixa qualidade dos materiais escolares fornecidos pelo almoxarifado, da Capital. Tal queixa atravessa os vários anos relatados na documentação. Já em 1933, Francisco de Faria Netto, delegado regional do ensino de Piracicaba, numa longa análise da importância dos materiais escolares, afirmava que

os meninos em idade escolar são obrigados à matrícula e à freqüência das aulas nas escolas primárias; o Estado tem o dever de supri-los do material necessário. E não o faz. As escolas públicas isoladas [rurais], em sua maioria, vivem desertas de papel, livros, cadernos, lápis e até de giz, servindo-se as professoras de pedras calcárias e piçarra para a escrita no quadro negro e os alunos [servindo-se] de papel de embrulho usado, anúncios de cinema etc. Como podem produzir essas funcionárias se o Governo lhes corta os braços? (Netto, 1933, p. 87)

Usando de ironia, o mesmo Francisco de Faria Netto, em 1942, agora como delegado regional do ensino de São Carlos, retornou ao tema:

A falta de material para as escolas isoladas [rurais] tem sido, até certo ponto, uma das diversas causas do pouco rendimento escolar. Tem sido um terço [do necessário] o material fornecido. Seria interessante que a Companhia Paulista de Estradas de Ferro resolvesse dar somente um terço do lubrificante necessário para o funcionamento de suas inúmeras composições que, diariamente, percorrem suas linhas e que os dois terços restantes fossem completados por seus empregados. (Netto, 1942, p. 11)

Com baixos salários, risco constante de contágio de doenças endêmicas, péssimas condições sanitárias nas escolas, freqüentemente sem serviço sanitário, moradia precária e escasso material escolar, era improvável que o professor das escolas rurais suportasse lecionar sob estas condições por muito tempo. Daí os constantes pedidos de licença ou de remoção para escolas urbanas tão logo fosse possível. 
Quais as principais reivindicações dos administradores escolares para minimizar este panorama profundamente negativo da educação nas escolas rurais do Estado de São Paulo? A recomendação mais freqüente é a de melhoria da remuneração do professor em escolas rurais e a diferenciação salarial em relação aos professores urbanos. Esta vantagem salarial auxiliaria a manter o professor no campo. O salário-base dos professores, tanto nas zonas rurais, quanto nas cidades, era de $300 \$ 000$. Para uma comparação, o salário de um servente era de $170 \$ 000$. O salário de um veterinário ligado ao serviço público era de $1.500 \$ 000$. Luiz Damasco Penna, delegado regional do ensino de Santos, no relatório referente a 1935, propõe uma remuneração diferenciada para o professor rural, tendo como referência a distância de sua escola em relação à ferrovia mais próxima, principal meio de transporte de então. Em círculos concêntricos, o professor que lecionasse a mais de $12 \mathrm{~km}$ da ferrovia mais próxima passaria a receber $500 \$ 000$. Para as escolas a mais de $40 \mathrm{~km}$ da ferrovia, o salário docente deveria ser de 1.000\$000. Para ele, tal medida manteria o professor rural em sua escola.

Este experiente administrador escolar concluiu seu raciocínio com um lacônico "as coisas são como são" (Penna, 1935, p. 32). Francisco Alves Mourão, delegado regional do ensino de Ribeirão Preto, em 1936, reivindicou a diferenciação da carreira do magistério, dividindo-a entre professores rurais e professores urbanos. Os primeiros com o salário-base de $500 \$ 000$ e a manutenção da remuneração de $300 \$ 000$ para os professores urbanos. Poderiam ser citadas diversas outras manifestações neste sentido, como as dos delegados regionais do ensino de Itapetininga em 1936, p. 60, Fernando Rios; de Araraquara no mesmo ano, p. 30-31, Ottoni Pompeu Piza; ou Lino Avancini, de Lins, em 1942, p. 18, ao ressaltar que, ou se melhorava o salário do professor rural, ou ele ficaria contando nos dedos os dias que faltavam para sair do lugar ao qual maldizia. $O$ Código de Educação do Estado de São Paulo, de 1933, previa uma gratificação anual suplementar de $600 \$ 000$, dois salários-base a mais, para os professores rurais. No entanto, vinculava esta gratificação anual a critérios inviáveis de rendimento escolar para as escolas rurais do período, pois o professor deveria comprovar que lecionara 200 dias letivos na mesma escola, com frequência de no mínimo 25 alunos e promoção anual de $75 \%$ deles.

Neste contexto, surgiam as principais críticas dos administradores escolares quanto ao processo de avaliação nas escolas rurais. Nesta época, o ano letivo começava em $1^{\circ}$ de fevereiro e terminava em 30 de novembro, com férias de duas semanas na segunda quinzena de junho, coincidindo este recesso com as festas juninas. $O$ mês de novembro era então dedicado aos exames finais em todas as escolas, urbanas ou rurais. Contudo, novembro era o mês mais importante para o trabalho de colheita agrícola nas zonas rurais. Os administradores escolares afirmavam que era inapropriado avaliar o rendimento escolar dos alunos somente pelos exames finais, ao término do ano letivo. Reivindicavam uma mudança no processo avaliativo de todos os alunos, quer fossem de escolas urbanas ou rurais. Devia-se avaliá-lo continuamente, pelas atividades durante todo o ano letivo. Como exemplo desta argumentação, pode-se citar João Teixeira de Lara, delegado regional do ensino de Botucatu, em 1933:

A promoção deveria ser baseada no trabalho efetivo e contínuo de todo o ano, o que facilmente, poderia ser verificado pelas autoridades escolares, na sua última visita à escola, no mês de novembro. Nessa visita, que seria 
bastante demorada, as autoridades verificariam, além de provas periódicas, os cadernos de linguagem, cálculo, desenho, caligrafia etc. [...] Para que fossem recompensados os professores no seu trabalho, principalmente os das escolas rurais, em que a instabilidade dos alunos é um fato, seria de vantagem a adoção de medidas como as que sugerimos. (Lara, 1933, p. 24)

No caso específico das escolas rurais, reivindicavam, ao menos, a antecipação dos exames finais para setembro. No final de setembro, geralmente, terminavam os contratos anuais de trabalho entre os fazendeiros e os colonos. Antes da colheita do café, cujo ápice ocorria em novembro, era quando os colonos podiam negociar novos contratos anuais em outras fazendas. Em outubro muitos colonos mudavam de fazenda, levando seus filhos com eles. Portanto, era comum o professor da escola rural educar seus alunos eficientemente e não vê-los promovidos de ano por não terem feito os exames finais em novembro. Valdomiro Guerra Corrêa, delegado regional do ensino de São Carlos, em 1933, propôs um calendário específico para as escolas rurais:

É de grande vantagem para o ensino e de imprescindível necessidade determinar-se que os exames finais das escolas das zonas cafeeiras se realizem em setembro, último mês do ano agrícola. Sem interrupção dos trabalhos escolares, a matrícula nessas [escolas] isoladas seria a contar de $1^{\circ}$ de outubro e as férias de inverno e verão acompanhariam os demais estabelecimentos de educação. É exato e firmemente afirmado pelos senhores inspetores o fato dessas escolas terem muitas eliminações no referido mês e matrícula de analfabetos em setembro e outubro, isso tudo com prejuízos dos resultados finais dos professores e quiçá de todas as [escolas] isoladas desses núcleos em nosso Estado. (Corrêa, 1933, p. 77)

Alguma solução paliativa foi tomada pela Diretoria Geral do Ensino, pois este tipo de reivindicação desapareceu dos relatórios após 1934 .

Uma das mais contundentes e repetidas críticas ao ensino rural paulista cabe à má formação docente para enfrentar as especificidades da educação na zona rural. As escolas normais eram todas urbanas e formavam profissionais, predominantemente, de origem urbana, para trabalhar com alunos em grupos escolares urbanos, desenvolvendo seus estágios de prática de ensino em escolas urbanas. Como tais profissionais poderiam ser adequados para lecionar em escolas isoladas rurais? João Teixeira de Lara, delegado regional do ensino de Piracicaba, sintetizou estas críticas:

O regime atual de grupo escolar dado ao Curso Primário anexo às Escolas Normais é anormal e prejudicial ao fim a que se destinam estas unidades escolares. A função da escola de professores é, precipuamente, fornecer professores para as escolas isoladas, porque é a escola isolada a célula mater de todo o ensino público. É para ela que vão os recém-formados. Para o trabalho nesse tipo e gênero de escola é que devem eles ser preparados. Em vez de um grupo fidalgo de dez classes, que reúne a elite infantil da cidade, constituída de crianças apatacadas [endinheiradas], superalimentadas, às quais não faltam recursos para a compra de material e formam um ambiente oposto àquele em que vão trabalhar os novos professores. (Lara, 1940, p. 45) 
O que alguns delegados do ensino propunham para sanar o problema da má formação docente e sua inadequação para lecionar em escolas rurais? Algo inédito até então: a criação de escolas normais rurais. Ao redigir sua análise dos resultados da pesquisa com os professores rurais de Piracicaba em 1933, Francisco de Faria Netto foi bem claro nesta proposta:

Sou pela localização das Escolas Normais primárias nos núcleos rurais de mais densa população pelos seguintes motivos: a - O professor para a zona rural deve ser escolhido no meio rural. b - O processo mais razoável para se conseguir a pessoa vocacionada para o magistério primário e adaptável às necessidades da zona rural é localizar a Escola Normal nesse meio; e c - Assim localizada, a Escola Normal selecionará paulatinamente os candidatos, descobrindo os vocacionados ao magistério rural, e aproveitando as belas inteligências que se desabrocham nos campos, as quais desenvolvidas e orientadas serão em futuro próximo as empenhadas nas soluções dos problemas rurais, nascendo então a nova fase fecunda da sólida e desejada civilização rural. O programa das Escolas Normais deve ser organizado sob um espírito fundamentalmente prático, visando o desenvolvimento de tudo aquilo que constitua a atividade, a vida da população rural. O programa deve ser organizado com o espírito fundamentalmente rural, tendo por primário objetivo o despertamento das inteligências nascidas no campo, de modo a criar nos indivíduos a convicção de que a vida ideal, nobre e feliz é a que o campo proporciona a quem a ele se dedica convenientemente orientado. Um programa que estude os homens em suas múltiplas relações com as coisas rurais e que possa habilitar os alunos que o estudem sobre tudo a viverem inteligentemente no campo. Os lentes [professores de nível secundário] para estas Escolas Normais não devem ter grande apego à vida urbana. As escolas agrícolas do país por certo poderão fornecer bons lentes. (Netto, 1933, p. 26)

Luiz Damasco Penna, delegado regional do ensino de Santos, no relatório referente a 1936, resumiu o dilema sobre a formação docente para as escolas rurais de maneira bem sucinta: ou se levava o conforto das cidades para o campo, com a finalidade de adaptação de professores urbanos ao mundo rural, ou se deveria criar escolas normais na zona rural, com o propósito de formar professores no próprio campo. Ele não acreditava na viabilidade de escolas normais rurais e defendia ser menos utópico, gradativamente, fornecer condições apropriadas de uma vida digna aos professores rurais:

A adaptação [do professor rural] ao local é o leitmotiv [motivo lógico] dos que propugnam a criação de um tipo especial de Escola Normal para formar professores rurais. Porque se cuida, penso, da instalação no local julgado pior, na roça, em suma. [...] [Enquanto isto não ocorre], de duas, uma: ou fazem transportar para a roça o conforto mínimo da cidade [...] ou se propõem a converter toda uma geração de moços [os professores rurais] em anacoretas [eremitas], com que utilidade não sei. E então, o Estado ou instala ele mesmo condignamente o professor, fazendo pouco a pouco, fazendo e mobiliando, casas para as escolas rurais, ou dá a esse professor meios de se instalar, isto é, paga ao professor rural gratificações adicionais que the permitam viver vida humana. Porque tudo custa dinheiro, isso é que não há dúvida. A vida na roça é caríssima. (Penna, 1936, p. 116) 
Sobre a educação rural paulista existe, ainda, um assunto de destaque na documentação estudada. É o que trata das escolas rurais japonesas e da necessidade de nacionalização do ensino no Brasil. Este tema não afetou o Estado de São Paulo por inteiro, mas principalmente as regiões de Santos, Jaboticabal, Santa Cruz do Rio Pardo e Lins.

A periodização clássica sobre o primeiro e longevo governo getulista, tomando a história política como marco referencial, se divide em três fases: 1930 a 1934, Governo Provisório; 1934 a 1937, Governo Constitucional; 1937 a 1945, ditadura do Estado Novo. A documentação aqui analisada atravessa estas três fases. Contudo, esta periodização não é adequada para a compreensão dos acontecimentos relacionados às escolas rurais paulistas durante este longo tempo. Até agora houve indiferença em contextualizar se os relatos citados ocorreram antes ou depois da instauração da ditadura do Estado Novo. A análise temática sobre as escolas rurais não apresentou diferenças significativas se a documentação havia sido produzida durante o período provisório, constitucional ou ditatorial do primeiro governo de Getúlio Vargas.

De certa maneira, confirmou-se a percepção que Max Weber teve do aparato burocrático dos Estados modernos, isto é, havia uma tendência de continuidade das políticas governamentais no que concerne às escolas públicas paulistas. Não houve grandes rupturas na gestão administrativa destas escolas. No entanto, isto não é válido para a documentação referente às escolas rurais japonesas. Existiu clara mudança nos relatos dos administradores escolares quando abordaram tais escolas rurais antes do Estado Novo e depois da instauração da ditadura de Getulio Vargas. O marco divisório ocorreu em 1938, quando a escalada autoritária do Estado Novo mudou o tratamento dado aos imigrantes. Esta alteração de política governamental resultou no decreto-lei $\mathrm{n}$. 3.010, de 20 de agosto de 1938. Este decreto normatizava a situação dos estrangeiros no Brasil e regulamentou o decreto-lei n. 406, de 4 de maio de 1938.

O decreto-lei n. 3.010/38, em 286 artigos, estabeleceu cotas e critérios rígidos de imigração. Detalhava, minuciosamente, as condições para a permanência de imigrantes no Brasil, prevendo a possibilidade de deportação para os imigrantes que não se adaptassem à nova legislação. O decreto-lei n. 3.010/38, no artigo 168, proibiu que imigrantes pudessem ser professores em escolas rurais. Somente brasileiros natos poderiam lecionar em escolas rurais de núcleos de imigração estrangeira. Isto afetou a viabilidade das escolas em funcionamento até então nas zonas rurais de colonização japonesa.

Antes do Estado Novo, havia divergência no tratamento que os administradores escolares paulistas davam aos imigrantes japoneses. Alguns manifestavam antipatia, outros, admiração. Em 1936, Collatino Fagundes, delegado regional do ensino de Santa Cruz do Rio Pardo, relatou, de maneira desfavorável, a chegada de imigrantes japoneses à sua região:

Com o crescimento da onda imigratória ao nosso país, vemos que ela trouxe e continua trazendo em seu bojo nacionalidades das mais diversas. Desagregadas da terra-mater por força das circunstâncias, tais indivíduos, em maioria, aportando ao nosso território, aglomeram-se em associações, hasteiam bandeiras, desenvolvem propagandas por meio de livros e retratos, abrem escolas e multiplicam seus núcleos, cujos intuitos 
desconhecemos. Jornais, anúncios, letreiros, tudo é feito em sua linguagem própria. Ainda há poucos dias vi em um clichê [foto] de jornal o desembarque de uma leva de imigrantes japoneses recém-chegados. Lotado um trem com 5 ou 6 carros e posto em movimento, de todas as janelas do comboio desfraldaram-se pequenas bandeiras do Japão. E com esse apego à nação de origem, aumentam seus núcleos, fazem suas festas e não se deixam assimilar pela nossa gente nem pelos seus costumes. [...] A influência do estrangeiro em nossa língua, em nossos costumes precisa ser controlada. Para tanto, mister seria que as nossas leis fossem menos tolerantes e impusessem umas tantas condições ao imigrado que viesse colaborar conosco. Suas escolas deviam ser as mais fiscalizadas e também obrigadas a compartilhar das festas cívicas nos estabelecimentos estaduais. (Fagundes, 1936, p. 33)

Em contraposição, Silvio da Costa Neves, de Lins, no mesmo ano de 1936, manifestou apreço ao relatar as atividades da colônia japonesa de sua região:

[Entre os novos agricultores] avultam os japoneses em levas imigratórias que em trânsito pelos centros urbanos demandam os nossos sertões, onde se implantam. Só em 1936, dizem as estatísticas, entraram em Araçatuba 1.338 japoneses e em Lins, 234. Estabelecidos no bairro [zona rural], constroem logo um prédio para a escola, quase sempre de madeira, amplo e com muitas janelas. Dão-lhe mobiliário tosco, lousa e algum material. Pedem o professor à autoridade escolar. Se possível diplomado, melhor; do contrário o particular faz as suas vezes e, ao pé da nossa escola, dá-se, também, logo que possível, a aula da língua japonesa, que a Lei faculta e a colônia julga indispensável. (Neves, 1936, p. 10)

Silvio da Costa Neves descreveu algo inexistente na maioria das outras regiões de São Paulo: escolas particulares rurais. No Estado de São Paulo existiam escolas particulares de levas precedentes de imigrantes, como italianos ou alemães, mas eram todas urbanas. Os imigrantes japoneses, concentrados em zonas rurais, solicitavam aos administradores governamentais escolas oficiais. Eles construíam os prédios destas escolas em suas zonas rurais e requisitavam do governo professores para tais escolas. Entretanto, caso não conseguissem professores oficiais, contratavam professores brasileiros ou entre os próprios imigrantes. No primeiro caso, o ensino da língua japonesa era atividade complementar da escola. No segundo caso, as aulas eram ministradas em japonês. Sobre os hábitos educacionais dos imigrantes japoneses, ainda em 1936, Silvio da Costa Neves, delegado regional do ensino de Lins, reproduziu em seu relatório palavras favoráveis do gerente geral da fazenda Bastos, situada em Marília:

Ao examinar as dificuldades que se encontram nas escolas rurais, principalmente nas regiões afastadas do centro populoso, verifiquei que estes embaraços não surgiram recentemente. Os lavradores japoneses são os pioneiros da civilização, são os bandeirantes modernos, porque são os japoneses, em grande parte, que penetram e abrem estradas pelas matas virgens. Há grandes dificuldades por parte das autoridades de ensino de fiscalização, enquanto os japoneses, não tendo conhecimento sobre o assunto do ensino, deixam as escolas sem a orientação necessária, instruindo seus filhos por um modo inadequado. Este retardamento da criação de escolas públicas, quando mesmo não faltem, muitas vezes os pais, que não podendo ver seus filhos abandonados, sem receber instrução, estabelecem um modo de educação de que já estão 
acostumados. Deixar esses pequenos escolares em abandono, sem receber instrução? É um problema gravíssimo aos pais e sério e importante ao Estado. (Neves, 1936, p. 10)

Silvio da Costa Neves, em 1936, argumentava que era correto que os japoneses mantivessem suas escolas onde o Estado não as criara, pois era injusto deixar os filhos dos japoneses sem educação. Esta constatação foi usada para solicitação à Diretoria Geral do Ensino da abertura de mais escolas rurais na região de Lins:

Os pais dessas crianças, senhor Diretor, não querem ficar responsáveis pela ignorância de seus filhos e os ensinam ou mandam ensiná-los a seu modo. Quererá o Estado arcar com a responsabilidade, pela falta de escolas, que até eles, os nossos hóspedes, taxam de importante? Se outras razões não existissem para a disseminação de escolas estaduais por esta região, estas seriam bastante. (Neves, 1936, p. 11)

As duas regiões com maior concentração de imigrantes japoneses no Estado de São Paulo estavam sob a jurisdição das delegacias regionais do ensino de Santos e de Lins. Os relatórios referentes a 1936 destas duas regiões descreveram a proporção entre escolas oficiais e japonesas nestas áreas. Neste ano, a região de Santos, contava com 26 grupos escolares, seis deles em áreas de imigração japonesa. Entre as 134 escolas rurais da região de Santos, havia 43 escolas na zona de colonização japonesa. Destas, sete eram escolas particulares, onde se lecionava apenas em japonês. Nas escolas da região de Santos, $15 \%$ dos alunos eram filhos de japoneses.

Contudo, mais da metade deles freqüentava escolas exclusivamente japonesas, com professores lecionando em português ou apenas em japonês. Isto é, das 1.209 crianças em idade escolar filhos de japoneses, 621 freqüentavam escolas japonesas, enquanto outros 566 filhos de japoneses se dividiam entre as demais escolas da região. Para a região de Lins, os dados não foram tão minuciosos. No mesmo ano de 1936, existiam 169 escolas isoladas estatais. Não foi informado quantas destas escolas encontravam-se em zonas rurais de colonização japonesa. Além delas, havia 87 escolas particulares japonesas.

Das 87 escolas japonesas, 29 escolas contrataram professores que falavam português. Nelas, o ensino da língua japonesa era atividade complementar. As outras 58 escolas ministravam aulas exclusivamente em japonês. O que causava espanto ao delegado regional do ensino de Lins era a porcentagem de freqüência das crianças nas escolas rurais japonesas. Segundo Silvio da Costa Neves, nas escolas das zonas rurais de imigração japonesa, a freqüência média das crianças em idade escolar era de 94,84\%.

No relatório referente a 1936, o delegado regional do ensino de Santos, Luiz Damasco Penna, não entendia a educação dos filhos dos imigrantes japoneses como uma necessidade em separado das carências educacionais das demais crianças das zonas rurais. Segundo ele havia que nacionalizar os filhos dos japoneses, mas havia também que nacionalizar os demais brasileiros pobres desta região, quer fossem descendentes de indígenas, negros ou caiçaras. Havia que nacionalizar o brasileiro, isto é, todos nascidos no país:

Formar cidadãos com virtudes públicas e virtudes privadas é um dos grandes escopos da escola primária, máxime [especialmente] da escola 
pública. Há a nacionalizar não só o filho do imigrante, nem principalmente o filho do imigrante. A mera circunstância vegetativa do nascimento não outorga cidadania. Muito brasileiro de séculos haverá por aí afora mais distanciado da nacionalidade que muito filho de imigrante. E quando o brasileiro é paupérrimo como é regra quase geral, a dificuldade de sua assimilação ao grêmio nacional fica bem patenteada. [...] Confiada que está principalmente à escola a tarefa da nacionalização, nós deveríamos começar por apresentar casas, instalações e alunos brasileiros em condições de facilitar aquela assimilação. As escolas estrangeiras não nos convêm. Fechar a estrangeira e deixar nenhuma seria solução desastrada. O que há a fazer, a única coisa que se deve fazer, é instalar escolas melhores que as estrangeiras. Mas melhores não só nas zonas de imigrantes, como por toda parte. Precisamos nacionalizar o imigrante, é certo. Mas precisamos com igual urgência nacionalizar o brasileiro. Quando se fala de imigrante, ultimamente, é que se quer falar de japoneses. (Penna, 1936, p. 54)

Fechar a escola estrangeira e deixar nenhuma, infelizmente, tornou-se prática comum no período. No relatório referente a 1938, após a edição do decreto-lei n. 3.010/38, Luiz Damasco Penna preferiu silenciar sobre os conflitos advindos com o fechamento das escolas japonesas. Não é fácil hoje conceber o que estava por trás da sua necessidade em afirmar que o fechamento destas escolas "se operou da maneira mais suave possível, sem qualquer atrito" (Penna, 1938, p. 75):

Tudo já foi dito e redito. Mas vale recordar ainda. Tendo encontrado escolas estrangeiras, fomos aos poucos transformando estas escolas em brasileiras, a tal ponto que, pelo seu fechamento, já eram elas em verdade simples cursos de língua japonesa funcionando dentro de escolas estaduais. O fechamento [...] se operou da maneira mais suave possível, sem qualquer atrito e, o que mais vale, sem qualquer prejuízo para a população infantil, antes com lucro, do ponto de vista nacional. Não interessam mais comentários sobre a conveniência ou inconveniência da manutenção do aparelho escolar organizado pelos imigrantes. (Penna, 1938, p. 75)

Em outras regiões do Estado de São Paulo, o fechamento das escolas japonesas foi bastante conflituoso. O autoritarismo do Estado Novo propiciou que alguns administradores escolares apresentassem postura também autoritária no tratamento das escolas rurais japonesas. Neste ambiente autoritário, e devido ao início da Segunda Guerra Mundial, alguns administradores escolares paulistas passaram a descrever os imigrantes japoneses como inimigos da pátria. Os filhos dos imigrantes, brasileiros, deviam ser protegidos destes inimigos, seus pais, em escolas rurais brasileiras. Esta postura pode ser exemplificada pela proposta do inspetor escolar João Batista Afonso de Barros, exposta no relatório de Jaboticabal de 1940. Nela, o professor rural brasileiro foi apresentado como um cruzado em missão de nacionalizar os filhos dos infiéis, os japoneses. Ele propôs que os demais inspetores escolares deveriam suavizar a tarefa dos professores rurais brasileiros nesta cruzada contra os japoneses:

Lembrai-vos, colegas, que centenas e centenas de alqueires de terra da nossa zona rural transformaram-se em núcleos estrangeiros; que nesses núcleos, onde somente a terra é brasileira e tudo o mais é estrangeiro, a palavra Brasil não é pronunciada com o respeito e acatamento que 
merece; que nesses núcleos vêm funcionando escolas estrangeiras, regidas por estrangeiros e freqüentadas por centenas de crianças; que dessas crianças, muitas são brasileiras como alguns de nós; isto é, filhos de estrangeiros, nascidos no Brasil. Lembrai-vos, colegas, que os decretos 406 e 3.010 [de 1938] proíbem terminantemente o funcionamento dessas escolas; que o dever nos impõe a introdução imediata da escola brasileira nesses núcleos; que árdua vai ser a missão e difícil a tarefa do professor nesse ambiente; que além de grande dose de patriotismo, o professor precisa ter conforto moral e precisa ser prestigiado por todos nós, para que possa permanecer no bairro [zona rural]; que cumpre a nós procurar suavizar a tarefa do professor que, qual missionário de uma cruzada, vai cumprir o sagrado dever de nacionalizar o bairro estrangeiro, implantando no coração dos pequeninos o amor pelo Brasil. (Barros, 1940, p. 16)

Embora o decreto-lei n. 3.010/38 não tratasse especificamente deste assunto, depois dele parte dos administradores escolares paulistas passou a considerar o ensino da língua japonesa e o porte de material didático neste idioma atos subversivos. Mesmo Silvio da Costa Neves, anteriormente simpático aos imigrantes japoneses, agora delegado regional do ensino de Casa Branca, mudou, em 1939, sua abordagem acerca das escolas japonesas:

\begin{abstract}
É bem dever [informar] que em uma escola rural de São Simão, apreendeu a autoridade escolar nas bolsas das crianças, filhos de japoneses, cartilhas no idioma daquele país oriental. Procedidas as investigações, chegou-se à conclusão de que o ensino estaria sendo dado pelo próprio pai, intimado então a não repetir [o ocorrido]. Ainda há a hipótese de terem as crianças vindo de outras zonas, onde estudavam [em língua japonesa], conforme alegou o dono da casa [o pai das crianças]. Todavia a lição ficou. E a professora, espantada com o que aconteceu, é agora a sentinela avançada de fiscalização. (Neves, 1939, p. 19)
\end{abstract}

A estratégia de nacionalização, utilizando o medo contínuo de batidas policiais nas zonas rurais de imigração nipônica, foi descrita, sucintamente, por Miguel Omar Barreto, delegado regional do ensino de Presidente Prudente, em 1940: "Os japoneses, temendo nossa ação continuada, têm nos procurado para comunicar a extinção de escolas clandestinas e nos pedir localização [instalação] de escolas nossas" (Barreto, 1940, p. 22).

Segundo a documentação, a maior resistência ao fechamento das escolas rurais japonesas ocorreu na região de Lins. No relatório de 1942, Lino Avancini, delegado regional do ensino, anexou sua análise sobre o assunto. Ela havia sido exposta no ano anterior na reunião dos delegados regionais de ensino que ocorrera na Capital. A situação em Lins era explosiva. O fechamento das escolas rurais japonesas tornou-se tema de polêmica na imprensa da região. Além de buscar e fechar escolas rurais japonesas, em 1942, Lino Avancini ainda lidou com inquérito contra professores japoneses, que segundo o decreto-lei n. 3.010/38 poderiam ser deportados, caso não tivéssemos rompido relações diplomáticas com o Japão:

$\mathrm{Na}$ campanha de nacionalização do ensino que mantivemos sempre sistemática e eficiente, logramos intimar o fechamento, nos anos de 1940, 1941 e 1942, de quarenta e duas escolas clandestinas nipônicas. Dois professores japoneses reincidentes respondem a processos criminais, 
atualmente em mãos da autoridade judiciária local. [Tais professores eram] elementos inimigos do país e teimavam em fazer funcionar [essas escolas]. [...] Intimadas a fechamento, essas escolas surgiam de novo em outro local. (Avancini, 1942, p. 47)

Antes do rompimento das relações diplomáticas entre Brasil e Japão, em 28 de janeiro de 1942, travou-se nos jornais de Lins polêmica sobre o fechamento das escolas japonesas. O artigo contra o modo com que as escolas japonesas estavam sendo fechadas, sem substituição por escolas públicas para esta população, denominou a colônia japonesa de laboriosa e coesa. Este artigo foi publicado no jornal O Progresso, de Lins, em 27/11/1941. Três dias depois saiu a resposta de Lino Avancini no jornal Correio de Lins:

O que os japoneses querem com a escola clandestina é ensinar aos neobrasileiros, aos pequenos de oito a dez anos que ainda não conhecem nossa língua, o idioma da pátria distante e saudosa, que continuam amando e no que querem ser seguidos pelos seus filhos, filhos que o Japão continua a bem estimar. [...] Os japoneses não se satisfazem com os conhecimentos fornecidos pela nossa escola, querendo mais: falta-lhes o conhecimento do idioma japonês, falta-lhes o conhecimento das coisas da terra de origem, que interessa muito a eles, mas não pode interessar ao brasileiro que tem um pouco de amor à terra em que nasceu. (Avancini, 1942, p. 65)

Quatro anos após a sua proibição, o delegado regional do ensino de Lins ainda perseguia e interditava escolas japonesas clandestinas:

Foram fechadas também, nos dias 26 de fevereiro e 22 de abril de 1942 , duas escolas japonesas, sendo uma em Araçatuba e outra em Lins. A de Lins vinha funcionando há oito dias apenas. [...] Acontece que [essas escolas] fechadas aqui, surgem logo adiante, em outro local, com igual viço, a zombar das nossas leis excessivamente benévolas e das autoridades encarregadas dessa fiscalização. (Avancini, 1942, p. 47-59)

É provável que as escolas rurais japonesas tenham continuado a funcionar clandestinamente por todo o período estudado. No pós-guerra, sua função cultural foi ocupada pelas associações nipo-brasileiras, existentes até hoje em diversas regiões do Estado de São Paulo. Na região de Lins, ações de localização e fechamento das escolas rurais japonesas eram executadas por Lino Avancini, junto com Paulo Cardoso de Almeida, delegado de Polícia da cidade. Os professores destas escolas eram, freqüentemente, encarcerados como inimigos de guerra. $O$ material didático em língua japonesa apreendido era destruído. A forma de reação à xenofobia governamental e ao fechamento de suas escolas cindiu a antes laboriosa e coesa colônia japonesa. Após o término da guerra, esta divisão eclodiu em atos violentos contra os japoneses mais assimilados à cultura brasileira, denominados pelos radicais japoneses como corações sujos.

Mesmo com todas as críticas às condições educacionais das escolas rurais brasileiras e com o fechamento das bem-sucedidas escolas rurais japonesas, os administradores escolares do Estado de São Paulo ainda mantiveram alguma esperança de que este tipo de educação ganharia um pouco de dignidade. Às vezes descreveram a 
escola rural do futuro, como na idealização de Paulo Monte Serrat, delegado regional do ensino de São Carlos:

Um grande e bem feito rancho de sapé, de forma circular, sem paredes, com assentos toscos, mesas também como improvisadas; ocupando o centro, o estrado da professora, quadros negros de duas faces e tudo assim. Aprenderão em contato com a natureza, respirando ar puro, longe do bulício [agitação] da cidade, mas relativamente próximos do lar onde passarão a noite, para volver nas manhãs seguintes à escola típica, as crianças da localidade. [...] Com feição acentuadamente ruralista, porém, cuidando também das combinações estupendas das letras do alfabeto. Se outrora a escola era o reduto de férreos princípios, de cega disciplina, do regime da inflexível autoridade que dispunha de seus rebanhos como entendia, nestas escolas a obediência deve-se cultuar pelo amor, pela docilidade e o trabalho exercido pelo interesse de ver floridos os alegretes [vasos suspensos nas varandas e janelas]; cheios os bebedouros; repletos de verduras os canteiros e povoados de pintos e galinhas brancas os cercados; lebres em seus viveiros; o milho espigado na rocinha pelo próprio aluno organizada. Com o progresso do desenvolvimento escolar, a poesia nesse recanto há de imperar na igualdade para o bem comum, no interesse de produção como coroamento do trabalho racional, ordenado e edificante. Parece que já ouvimos longe os clamores da vitória do ensino rural, como um sonho que se materializa na hora do seu destino. (Serrat, 1943, p. 26)

Nos relatos do atual texto, vemos como os delegados regionais do ensino, inspetores escolares, diretores de grupos escolares e professores lutaram pela melhoria da educação da população rural. Luta freqüentemente frustrante, mas à qual se dedicaram com afinco. Paradoxalmente, as escolas rurais bem sucedidas, que contavam com apoio de suas comunidades, com professores bem adaptados ao ambiente rural, com a quase totalidade das crianças de seu entorno a freqüentá-las, por não empregar professores e materiais didáticos brasileiros, foram fechadas nesta tumultuada época. Esta foi a dramática sina das muitas escolas rurais japonesas do período. Neste caso, de maneira trágica, trocou-se o espírito de horror à vida educativa nos campos por atos concretos de terror à vida educativa nos campos. Tristes tempos.

\section{Referências}

AVANCINI, Lino. Relatório de Lins de 1942. Disponível em http://www.arquivoestado.sp.gov.br/upload/revistas/RDRLS1942.pdf. Acesso em 14 jul., 2012.

AZEVEDO, Francisco Lopes de. Relatório de Taubaté de 1935. Disponível em http://www.arquivoestado.sp.gov.br/upload/revistas/RDRTA1935.pdf. Acesso em 4 jul., 2012.

BARRETO, Miguel Omar. Relatório de Presidente Prudente de 1940. Disponível em http://www.arquivoestado.sp.gov.br/upload/revistas/RDRPP1940.pdf. Acesso em 17 jul., 2012.

BARROS, João Batista Afonso de. Relatório de Jaboticabal de 1940. Disponível em http://www.arquivoestado.sp.gov.br/upload/revistas/RDRJB1940.pdf. Acesso em 13 jul., 2012. 
CELESTE FILHO, Macioniro. Os relatórios das Delegacias Regionais de Ensino do Estado de São Paulo como fonte de pesquisa para a história da educação - décadas de 1930 e 1940. Revista Brasileira de História da Educação. Campinas: SBHE/Autores Associados, v. 12, n. 1, 2012, p. 71-111.

CLOZEL, José. Relatório de São José do Rio Preto de 1934. Disponível em http://www.arquivoestado.sp.gov.br/upload/revistas/RDRRI1934.pdf. Acesso em 11 jul., 2012.

CORREAA, Valdomiro Guerra. Relatório de São Carlos de 1933. Disponível em http://www.arquivoestado.sp.gov.br/upload/revistas/RDRSC1933.pdf. Acesso em 21 jul., 2012.

EBOLI, José Ferreira. Relatório de Guaratinguetá de 1943. Disponível em http://www.arquivoestado.sp.gov.br/upload/revistas/RDRGR1943.pdf. Acesso em 12 jul., 2012.

FAGUNDES, Collatino. Relatório de Santa Cruz do Rio Pardo de 1936. Disponível em http://www.arquivoestado.sp.gov.br/upload/revistas/RDRSR1936.pdf. Acesso em 23 jul., 2012.

GUELLI, Oscar Augusto. Relatório de Botucatu de 1940. Disponível em http://www.arquivoestado.sp.gov.br/upload/revistas/RDRB01940.pdf. Acesso em 12 jul., 2012.

LARA, João Teixeira de. Relatório de Botucatu de 1933. Disponível em http://www.arquivoestado.sp.gov.br/upload/revistas/RDRBO1933.pdf. Acesso em 10 jul., 2012.

LARA, João Teixeira de. Relatório de Piracicaba de 1940. Disponível em http://www.arquivoestado.sp.gov.br/upload/revistas/RDRPI1940.pdf. Acesso em 23 jul., jul., 2012.

LARA, João Teixeira de. Relatório de Piracicaba de 1942. Disponível em http://www.arquivoestado.sp.gov.br/upload/revistas/RDRPI1942.pdf. Acesso em 15 jul., 2012.

MOURÃO, Francisco Alves. Relatório de Ribeirão Preto de 1936. Disponível em http://www.arquivoestado.sp.gov.br/upload/revistas/RDRRP1936.pdf. Acesso em 3 jul., jul., 2012.

NETTO, Francisco de Faria. Relatório de Piracicaba de 1933. Disponível em http://www.arquivoestado.sp.gov.br/upload/revistas/RDRPI1933.pdf. Acesso em 29 jul., 2012.

NETTO, Francisco de Faria. Relatório de São Carlos de 1942. Disponível em http://www.arquivoestado.sp.gov.br/upload/revistas/RDRSC1942.pdf. Acesso em 30 jul., 2012.

NEVES, Silvio da Costa. Relatório de Lins de 1936. Disponível em http://www.arquivoestado.sp.gov.br/upload/revistas/RDRLS1936.pdf. Acesso em 29 jul., 2012.

NEVES, Silvio da Costa. Relatório de Casa Branca de 1939. Disponível em http://www.arquivoestado.sp.gov.br/upload/revistas/RDRCB1940.pdf. Acesso em 16 jul., 2012. 
PENNA, Luiz Damasco. Relatório de Santos de 1935. Disponível em http://www.arquivoestado.sp.gov.br/upload/revistas/RDRSA1936.pdf. Acesso em 13 jul., 2012.

PENNA, Luiz Damasco. Relatório de Santos de 1936. Disponível em http://www.arquivoestado.sp.gov.br/upload/revistas/RDRSA1937.pdf. Acesso em 15 jul., 2012.

PENNA, Luiz Damasco. Relatório de Santos de 1938. Disponível em http://www.arquivoestado.sp.gov.br/upload/revistas/RDRSA1939.pdf. Acesso em 17 jul., 2012.

PENNA, Luiz Damasco. Relatório de Santos de 1940. Disponível em http://www.arquivoestado.sp.gov.br/upload/revistas/RDRSA1941.pdf. Acesso em 18 jul., 2012.

PIZA, Ottoni Pompeu. Relatório de Araraquara de 1936. Disponível em http://www.arquivoestado.sp.gov.br/upload/revistas/RDRAR1936.pdf. Acesso em 23 jul., 2012.

RIOS, Fernando. Relatório de Itapetininga de 1936. Disponível em http://www.arquivoestado.sp.gov.br/upload/revistas/RDRIT1936.pdf. Acesso em 19 jul., 2012.

SERRAT, Paulo Monte. Relatório de São Carlos de 1943. Disponível em http://www.arquivoestado.sp.gov.br/upload/revistas/RDRSC1943.pdf. Acesso em 28 jul., 2012.

WEBER, Max. Parlamento e governo na Alemanha reordenada: crítica política da burocracia e da natureza dos partidos. Petrópolis: Vozes, 1993.

MACIONIRO CELESTE FILHO é professor da Unesp, campus de Bauru. Graduado em História pela USP, é mestre e doutor em Educação pela PUCSP.

Endereço: Avenida Paes de Barros, 1252/22 - 03114-000 - São Paulo - SP - Brasil.

E-mail: marcio.celeste@fc.unesp.br.

Recebido em 2 de maio de 2013.

Aceito em 8 de outubro de 2013. 